\title{
DETERMINANTS OF ANTENATAL CARE SERVICES UTILIZATION IN EMEVOR VILLAGE, NIGERIA
}

\author{
*V. O. Awusi, *E.B. Anyanwu, ${ }^{* *}$ V. Okeleke
}

"Department of Family Medicine, College of Medical Sciences, Delta State University, Abraka, Delta State, Nigeria.

"Central Hospital, Oleh, Isoko South Local Government Area, Delta State, Nigeria.

Correspondence:

Dr. V. O. Awusi

Department of Family Medicine

College of Medical Sciences

Delta State University, Abraka

Delta State, Nigeria.

Email: alpha.medicalcentre@yahoo.com

\section{ABSTRACT}

Appropriate ante-natal care services promotes safe-motherhood and delivery with improved maternal and neonatal outcome.

The aim of this cross-sectional study was to evaluate the factors influencing the utilization of ante-natal care services in a rural community. Of the 200 women studied, 113 (57\%) utilized ante-natal care services during pregnancy while 87 (43\%) did not. The difference is not significant $(P>0.05)$. A majority of the women who attained secondary education $(69 \%)$, post-secondary education (96\%), those whose husbands had secondary education (69\%), postsecondary education (82\%) and those who had income-yielding occupations (72\%) utilized ante-natal care services. While only $36 \%$ of full-time housewives, with no other occupation, and $19 \%$ of women with a parity of more than 4 children utilized ante-natal care services.

It is suggested that low-income, uneducated women with high parity should be targeted for enlightenment; in addition to promoting education of the girl-child and women empowerment.

Key words: Ante-natal care, determinants, utilization, rural, Nigeria.

\section{INTRODUCTION}

Ante-natal care (ANC) services indirectly saves the lives of mothers and babies by promoting and establishing good health before childbirth and the early post-natal period ${ }^{1}$. It often presents the first contact opportunities for a pregnant woman to connect with health services, thus offering an entry point for integrated care, promoting healthy home practices, influencing care-seeking behaviours and linking women with pregnancy complications to a referral system; thus impacting positively on maternal and fetal health ${ }^{1}$. The very low maternal/infant morbidity and mortality rates reported for developed countries ${ }^{2}$ compared with the extremely high figures in developing countries ${ }^{2}$ have been attributed to the higher utilization of modern obstetric services by the former ${ }^{2}$. Currently, $71 \%$ of women worldwide utilizes ANC services; and in industrialised countries - $95 \%$, South Asia - 54\% and Sub-Saharan Africa $-64 \%{ }^{9}$.

Studies in developing countries have shown that the use of health-care services is related to the availability, quality and cost of services, as well as to the social structure, health beliefs and personal characteristics of the users ${ }^{3,4,5}$. In order to increase the uptake of ante- 
natal care services in a community, we need to understand the factors that underlie the decision of a pregnant woman to utilize the services. This is especially important in rural areas, where $64 \%$ of Nigerians resides ${ }^{6}$. This study, therefore, set out to assess the utilization of ante-natal care services and identify factors associated with it in a rural community in Delta State of Nigeria.

\section{MATERIALS AND METHODS}

Emevor village is located in Isoko North L. G. A. of Delta State and, it is about 20 Kilometer from the Local Government headquarter of Isoko south, Oleh, where a Central hospital, which serves as a district referral centre for the whole of Isoko district, is located. The village has a total estimated population of about 8,000 people (figures as at 2007 , from the Local government council). It has a Maternity/ Nursing Home which offered midwife-led ante-natal and delivery care with no facilities for surgical intervention. Patients requiring operative delivery are referred to the district hospital. Informed consent was obtained from the participants in this study.

This was a cross-sectional study in which households were numbered and a one in three sample was selected using the systematic sampling method. A convenient sample size of 200 was used.

Two hundred women who were either pregnant or had previous deliveries were interviewed using pretested structured questionnaires. Information was collected on socio-demographic characteristics, attendance at ante-natal clinic( minimum of 3 ANC visits ${ }^{9}$ in index or any previous pregnancy, of the 5years preceding the survey; and also for Gravida $1\left(1^{\text {st }}\right.$ pregnancy ) women, ANC services was deemed to have been utilized if at least she has registered for ante-natal care in any health facility with only a promise to keep $\geq 2$ of her ANC visit appointments before delivery ) during pregnancy and reasons for nonutilization of such services.
The computer programme, Epi Info Version 5 (USD Inc., Georgia, 1990) ${ }^{16}$ was used to process the data. The statistical methods applied included means, percentages and the student's ttest/chi-square (where applicable) of independence between variables. The level of significance was set at $5 \%(\mathrm{P}<$ 0.05).

\section{RESULTS}

The age of the respondents ranged from 14 - 44 years with a median age of 27 years. One hundred and thirteen $(57 \%)$ of the respondents utilized ante-natal care services in the community, while 87 $(43 \%)$ did not. This was not significant $(t$ $=1.527$, df $=26, \mathrm{P}>0.05$ ) (Table I). It also shows that $99(87.6 \%)$ younger women, age less than 31years, utilized ANC services compared with only 14 $(12.4 \%)$ of the older women, aged more than 30 years.

The influence of the women' and their husbands' educational status on utilization of ANC services in the community is shown in Table I. It shows that $96 \%$ of the women with postsecondary education and, $69 \%$ and $46 \%$ of those with secondary and primary education, respectively, utilized the services. Only $23 \%$ of women with no formal education attended ANC during pregnancy. There was a higher percentage of ANC services utilization among women whose husbands had post-secondary (81\%) and secondary (69\%) education. Only $18 \%$ and $27 \%$, respectively, of women whose husbands had primary and no formal education, utilized ANC services. Conversely, the highest percentage of women who did not utilize the services was found among women whose husbands had primary $(82 \%)$ and no formal $(73 \%)$ education.

The influence of the women's occupation on the utilization of ANC services is also shown in Table I. It shows that all $(100 \%)$ of those who were civil servants and, $75 \%$ and $48 \%$, respectively, of the traders and farmers 
utilized the services; while only $36 \%$ of the full-time housewives did so.

Table I: SOCIO-DEMOGRAPHIC CHARACTERISTICS OF THE STUDY POPULATION.

\begin{tabular}{|c|c|c|c|}
\hline Variable & Utilized ANC N=113 (57) & No ANC $N=87(43)$ & P-value \\
\hline Age group & $2(40)$ & $3(60)$ & \\
\hline$<16$ & $12(67)$ & $6(33)$ & \\
\hline $16-20$ & $24(63)$ & $14(37)$ & \\
\hline $21-25$ & $61(69)$ & $27(31)$ & \\
\hline $26-30$ & $10(29)$ & $24(71)$ & $<0.05$ \\
\hline $31-35$ & $3(27)$ & $8(73)$ & \\
\hline $\begin{array}{c}36-40 \\
>40\end{array}$ & $1(17)$ & $5(83)$ & \\
\hline Respondents' occupation & $30(48)$ & $33(52)$ & \\
\hline Farmer & $24(75)$ & $8(25)$ & \\
\hline Trader & $22(100)$ & 0 (0) & \\
\hline Civil servant & $20(36)$ & $36(64)$ & $<0.05$ \\
\hline House-wife & $17(63)$ & $10(37)$ & \\
\hline Respondents' level of education & $6(23)$ & $20(77)$ & \\
\hline None & $38(6)$ & $45(54)$ & \\
\hline Primary & $46(69)$ & $21(31)$ & \\
\hline Secondary & $23(96)$ & $1(4)$ & $<0.05$ \\
\hline Post-secondary & & & \\
\hline Level of education of husband & & & \\
\hline None & $3(27)$ & $8(73)$ & \\
\hline Primary & $9(18)$ & 40 (82) & \\
\hline Secondary & $72(69)$ & $32(31)$ & $<0.05$ \\
\hline Post-secondary & 29 (81) & 7 (19) & \\
\hline
\end{tabular}

The role played by the women's parity on the utilization of ANC services is shown in Table II. It shows that only $19 \%$ of women with a parity of more than 4 children utilized the services, while $71.5 \%$ of those with a parity of 1-4 did so. Conversely, $81 \%$ of women with a parity of more than 4 did not utilize ANC services during pregnancy.
Reasons given by women for nonutilization of ante-natal care services included "I am well" (45\%) and traditional/ spiritual care preferred (25\%). Other reasons included not affordable (15\%), husband's disapproval $(6 \%)$ and lack of transport $(9 \%)$.

Table II: INFLUENCE OF PARTYY ONUTLZATION OF ANC SERMCES

\begin{tabular}{|c|c|c|c|}
\hline Birth Order & $\begin{array}{c}\text { Utilize ANC services } \\
\text { No. (\%) }\end{array}$ & $\begin{array}{c}\text { Do not utilize ANC } \\
\text { services No. (\%) }\end{array}$ & Total \\
First Pregnancy & $17(71)$ & $7(29)$ & 24 \\
1 & $35(83)$ & $7(17)$ & 42 \\
$2-4$ & $52(60)$ & $34(40)$ & 86 \\
$>4$ & $9(19)$ & $39(81)$ & 48 \\
Total & $\mathbf{1 1 3 ( 5 7 )}$ & $\mathbf{8 7}(\mathbf{4 3})$ & $\mathbf{2 0 0}$ \\
\hline
\end{tabular}




\section{DISCUSSION}

This study reports that the women in Emevor community do not adequately utilize ANC services during pregnancy (at least within the past 5 years preceding the survey). The nonutilization rate of $43 \%$, found in this study, was very high when compared to the less than 5\% reported for industrialized countries ${ }^{9}$. It is, however, comparable to the non-utilization rates of ANC services reported for Kumbotso village in Kano, Nigeria $41 \%^{5}$, llesa in Osun, Nigeria $-45 \%{ }^{7}$ and the national average for India $44 \%{ }^{8}$. It was higher than the average non-utilization rate of ANC services reported for Africa - $36 \%{ }^{9}$ but, however, it was lower than the national average reported for Nigeria - 53\% 10 and for South Asia $-46 \%{ }^{9}$.

Reasons given for non-utilization of ANC services in the studied population, which included lack of motivation, non-accessibility, cultural and negative role played by husbands, are similar to findings elsewhere ${ }^{2,4,5}$. The low attendance rates noted among the older women, aged more than 30years, in this study and other studies $^{5,12}$ could be due to overconfidence, being ignorant of increased pregnancy-related complication(s) risk with advancing age and parity ${ }^{4}$.

Higher educational attainment of both the women and their husbands had a positive influence on the utilization of ANC services in the studied population, as also observed in other studies ${ }^{4,5,11,15}$. In this study, $96 \%$ and $81 \%$, respectively, of the women and those whose husbands had postsecondary education utilized the services. Conversely, $77 \%$ and $73 \%$ of women and those whose husbands had no formal education, respectively, did not utilize ANC services during pregnancy. Pathways through which education acts include greater knowledge and awareness of the benefits of ANC services, greater ability to travel outside the home to seek care and perhaps a greater decision-making power at home ${ }^{12,13}$. Therefore, the education of the community, including the girl-child, could decrease maternal and neonatal mortality in the long term ${ }^{4,9,10}$.

As in other studies ${ }^{5,8}$, incomegenerating occupations of the studied women had positive influence on the rate of utilization of ANC services in the community; as all the civil servants $(100 \%)$, traders $(75 \%)$ and the farmers $(48 \%)$ had higher ANC utilization status more than those who were fulltime house wives with no other occupation (36\%). Therefore, empowering the women economically could lead to higher ANC services utilization $^{5,8,9}$ and impact positively on maternal and child health ${ }^{9,14}$.

Another important observation which emerged during analysis of the results pertain to the role played by the women's parity in the utilization of ANC services. It was found that only $19 \%$ of women with a parity of more than four children utilized the ANC services during pregnancy compared to the $71 \%$ utilization rate found among women with parity of four or less (Table II). This is similar to other studies $^{3,12,13}$ which found that a higher birth order decreases the use of maternal health-care services. Reasons ascribed to this attitude included the experience women gain with each succeeding pregnancy and childbirth, and the time and cost pressures associated with larger families, which decrease utilization.

In conclusion, the study has shown that women in Emevor community do not significantly utilize ANC services during pregnancy; and that lower age/ parity of the woman, higher educational attainment of both the woman and husband and, incomeearning by the women had a positive impact on the rate of ANC services 
utilization. It is, therefore, recommended that low-income, uneducated women with high birth order should be targeted for outreach and education by an integrated maternal and child health programme. Secondly, the women's education and economic status should be optimized. Thirdly, quality infrastructure and health facilities should be available and easily accessible in the rural areas; and where such facilities are not available, mobile clinics or outreach workers (community health officers, midwives etc) should be available on a regular basis. Finally, from a research perspective, more work is needed to understanding the family decision-making dynamics and how they impact health services utilization.

\section{ACKNOWLEDGEMENT}

We wish to thank all the medical doctors and medical assistants of the Central hospital, Oleh, for their full participation in this study. Finally, our special gratitude goes to all the households, men and women, who were selected and who participated in the survey.

\section{REFERENCES}

1. Bulatoo RA, Ross JA. Rating maternal and Neonatal Health Programs in Developing Countries. Chapel Hill, NC: MEASURE Evaluation Project, University of North Carolina, Carolina Population Centre. 2000.

2. World Health Organization. Advancing Safe Motherhood through Human Rights. New-York: Reproductive Health Publications, 2001.

3. Chakraborty N, Islam MA, Chowdhury RI, Bari W. Utilization of post-natal care in Bangladesh: evidence from a longitudinal study.
HIth. Soc. Care Community 2002; 10: 492-502.

4. Kulmala T, Vaahtera M, Rannikko $J$. The relationship between antenatal risk characteristics, place of delivery and adverse delivery outcome in rural Malawi. Acta Obstet. Gynaecol. Scand. 2000; 79: 984-90.

5. Kabir M, Iliyasu Z, Abubakar IS, Sani AA. Determinants of utilization of ante-natal care services in Kumbotso village, Northern Nigeria. Trop. Doct. 2005; 35: 110-111.

6. Population Reference Bureau. 2001. 2001 World Population Data Sheet. Washington, DC: Population Reference Bureau. http://www.prb.org/Content/Navigati onMenu/Other reports/20002002/sheet4.htm1 Accessed $13 / 06 / 09$.

7. Ogunlesi TA, Okeniyi JA, Owa JA, Oyedeji GA. Neonatal tetanus at the close of the $20^{\text {th }}$ century in Nigeria. Trop. Doct. 2007; 37: 1657.

8. Manju R, Sekhar B. and Steve Harvey. Differentials in the quality of ante-natal care in India. Int. J. Quality HIth. Care 2008; 20(1): 6271.

9. Opportunities for Africa's Newborn: Practical Data, Policy and Programmatic Support for New Born Care in Africa. Joy Lawn and Kate Kerber, eds. PMNCH, Cape Town, 2006. ISBN- 13: 978-0-62037695-2 and ISBN-10:0-62037695-3.

10. National Population Commission (NPC) Nigeria and ORC Macro. 2004. Nigeria Demographic and Health Survey 2003. Calverton, 
Maryland: National Population Commission and ORC Macro.

11. Magadi MA, Madise NJ, Rodrigues RN. Frequency and timing of antenatal care in Kenya: explaining the variations between women of different communities. Soc. Sci. Med. 2000; 51: 551-61.

12. Navaneetham K, Dharmalingam A. Utilization of maternal health care services in Southern India. Soc. Sci. Med. 2002; 55: 1849-69.

13. Amardeep T. Determinants of tetanus toxoid immunisation in pregnancy in rural Bihar. Trop. Doct. 2005; 35: 75-7.
14. Ram F, Sigh A. Is ante-natal care effective in improving maternal health in rural Uttar Pradesh? Evidence from a District Level Household Survey. J. Bios. Sci. 2006; 38: 433-48.

15. Bawa SB, Umar US, Onadeko M. Utilization of Obstetric Care Services in a Rural Community in South Western Nigeria. African Journal of Medicine and Medical Sciences 2004; 33(3): 239-44.

16. Dean AG, Dean JA, Burton AA, Dicker RG. Epi Info Version 5: A word processing database and statistical system for epidemiology on microcomputers. Stone Mountain. USD incorporated, Georgia, 1990. 